\title{
Insecticide susceptibility of Anopheles stephensi to DDT and current insecticides in an elimination area in Iran
}

\author{
Mehdi Zare ${ }^{1}$, Moussa Soleimani-Ahmadi ${ }^{2,3^{*}}$, Sayed Hossein Davoodi ${ }^{4}$ and Alireza Sanei-Dehkordi ${ }^{2,3}$
}

\begin{abstract}
Background: Iran has recently initiated a malaria elimination program with emphasis on vector control strategies which are heavily reliant on indoor residual spraying and long-lasting insecticidal nets. Insecticide resistance seriously threatens the efficacy of vector control strategies. This study was conducted to determine the insecticide susceptibility of Anopheles stephensi to DDT and current insecticides in Jask county as an active malaria focus in southeastern Iran.

Methods: In this study, the anopheline larvae were collected from different aquatic habitats in Jask county and transported to insectarium, fed with sugar and then 3-day-old adults were used for susceptibility tests. WHO insecticide susceptibility tests were performed with DDT (4 \%), malathion (5\%), lambda-cyhalothrin (0.05\%), deltamethrin (0.05\%) and permethrin (0.75\%).

Results: The field strain of An. stephensi was found resistant to DDT and lambda-cyhalothrin. The $L T_{50}$ values for DDT and lambda-cyhalothrin in this species were 130.25, and $37.71 \mathrm{~min}$, respectively. Moreover, An. stephensi was completely susceptible to malathion and permethrin and tolerant to deltamethrin.

Conclusion: The present study results confirm the resistance of the major malaria vector, An. stephensi, to DDT and lambda-cyhalothrin, and tolerance to deltamethrin, which could gradually increase and spread into other malaria endemic areas. Thus, there is a need for regular monitoring of insecticide resistance in order to select suitable insecticides for vector control interventions towards malaria elimination.
\end{abstract}

Keywords: Insecticide resistance, Anopheles stephensi, Malaria, Jask, Iran

\section{Background}

Malaria is one of the foremost public health problems in Iran. Recent studies on anopheline mosquitoes in Iran have reported the presence of eight malaria vectors [1]. In the southeastern Iran six species have been incriminated as malaria vectors, i.e. Anopheles culicifacies, An. dthali, An. fluviatilis, An. stephensi, An. superpictus and An. pulcherrimus, noting that the major vector in the area is An. stephensi [1-3].

\footnotetext{
* Correspondence: mussa.soleimani@yahoo.com

${ }^{2}$ Social Determinants in Health Promotion Research Center, Hormozgan University of Medical Sciences, Bandar Abbas, Iran

${ }^{3}$ Department of Medical Entomology and Vector Control, Faculty of Health, Hormozgan University of Medical Sciences, P.O. Box: 79145-3838, Bandar Abbas, Iran

Full list of author information is available at the end of the article
}

The initial malaria eradication campaign was initiated in Iran in 1951 and changed to malaria control in 1985 as a result of constraints and challenges [4]. Iran has been in the current elimination phase since 2010 and the number of indigenous cases were reduced from 1850 cases in 2010 to 358 in 2014 [5]. At present, almost all regions are free of the disease, with the exception of the thinly populated southeastern tropical part of the country near the border with Pakistan (Fig. 1). This area has two seasonal peaks in spring and autumn $[1,6]$.

Vector control is the main component of the malaria control strategy, which aims to prevent parasite transmission through interventions targeting anopheline vectors [7]. The lack of an effective malaria vaccine and the presence or emergence of resistance to existing antimalarial drugs further increases the importance of vector 


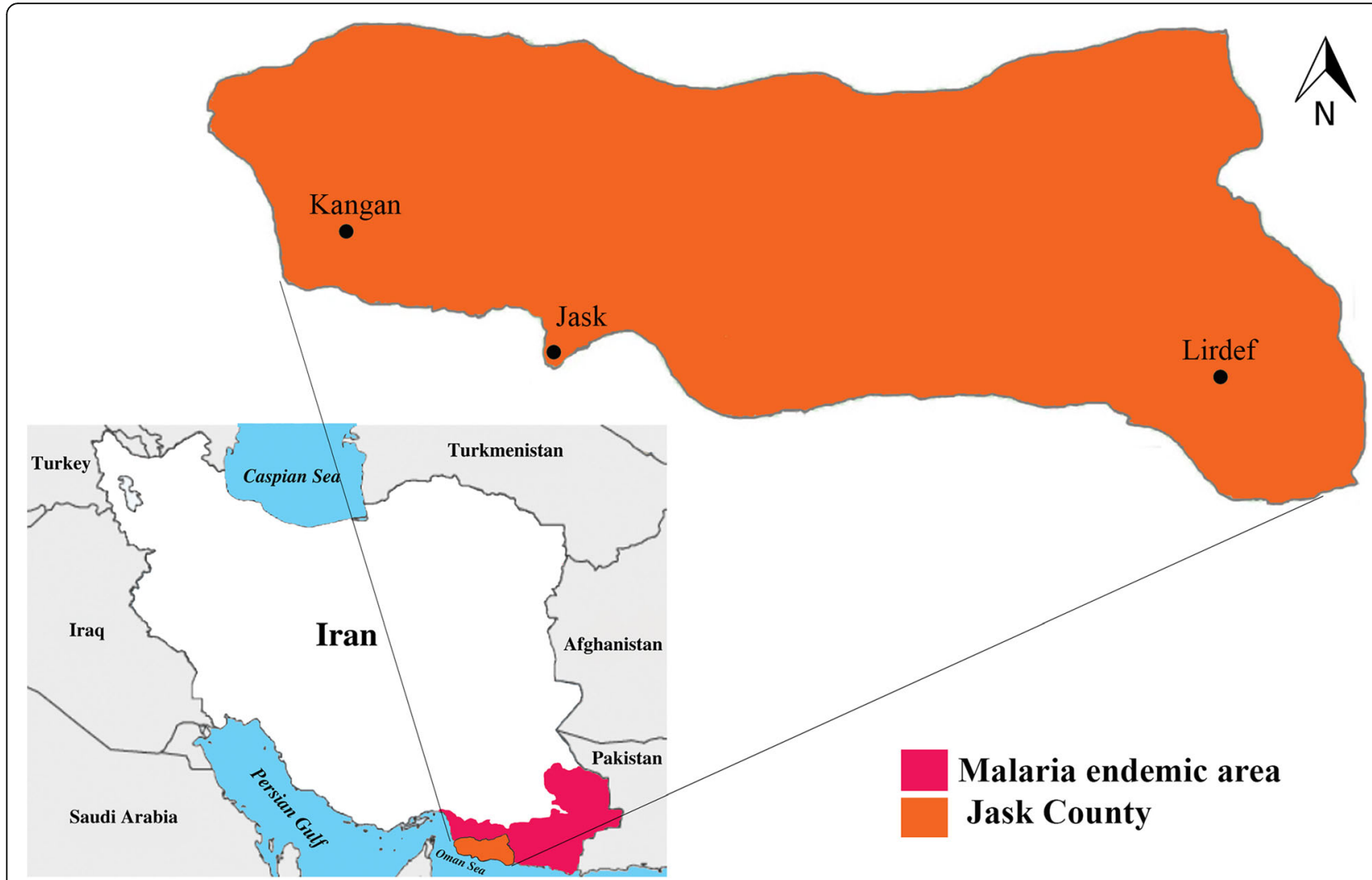

Fig. 1 Map of Iran, highlighting the location of malaria endemic areas and study area in Jask county

control measures [8]. Vector control for malaria is mainly composed of long-lasting insecticidal nets (LLINs) and indoor residual spraying (IRS) programmes which are highly dependent on pyrethroid insecticides [9]. These insecticides are the only class approved for use on LLINs and they are being increasingly used in IRS because of their low human toxicity, excito-repellent properties, rapid rate of knock-down and killing effects [10]. Moreover, pyrethroid insecticides are being widely used in the control of agricultural pests worldwide [11]. The extensive use of pyrethroids has increased the selection pressure on the major malaria vectors, which have inevitably developed resistance [12]. In Iran, resistance of the main malaria vector An. stephensi to DDT and malathion has been reported from the southeast areas, where the first indication of this species resistance to pyrethroid insecticides was reported in 2012 [13, 14].

Successful implementation of IRS and LLINs as the main malaria vector control strategies requires sound and up-to-date information on susceptibility of the anopheline species involved in malaria transmission to available insecticide compounds. Therefore this study was conducted to determine the susceptibility of natural population of An. stephensi as the major malaria vector to DDT and current insecticides in Jask county which is an active malaria focus under elimination programme in
Iran. The results of this study will provide information that would help in planning and implementing an effective program for vectors control during elimination phase by the National Malaria Control Program.

\section{Methods}

\section{Study area}

This study was carried out in Jask County in the Hormozgan province, southeastern Iran. The county has an area of $11,141 \mathrm{~km}^{2}$ and is located between latitudes $25^{\circ} 23^{\prime}-26^{\circ} 13^{\prime} \mathrm{N}$ and longitudes $57^{\circ} 10^{\prime}-59^{\circ} 16^{\prime} \mathrm{E}$, with an approximately 78,700 population in 2015 (Fig. 1). The Jask County has a dry and warm climate with hot summers and temperate winters and mean annual temperature of $26.8^{\circ} \mathrm{C}$ ranging from $18.7^{\circ} \mathrm{C}$ to $32.2{ }^{\circ} \mathrm{C}$. The rainy season occurs between December and May with an annual average of $106.7 \mathrm{~mm}$. The averages of minimum and maximum relative humidity are $47 \%$ in January and $85 \%$ in August, respectively (Fig. 2). More than $90 \%$ of the area is located in plain/coastal area with an altitude of less than $400 \mathrm{~m}$ and the rest is mountainous with an altitude of more than $400 \mathrm{~m}$. This county is an agricultural region irrigated by rivers which are the main breeding sites for anopheline mosquitoes. Agriculture, livestock herding, fishing and trading are the main occupations in the study area. 


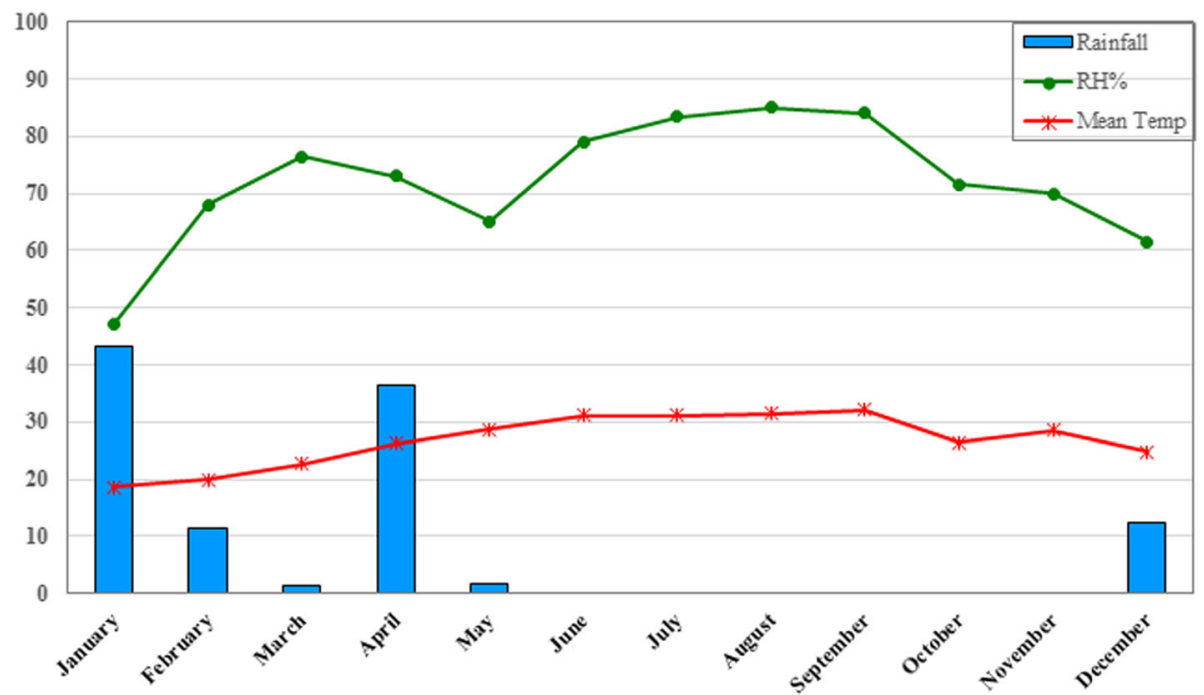

Fig. 2 Average of meteorological parameters during 2013-2014 in Jask county, southeastern Iran

Jask conty is one of the most active malaria foci in the southeast of Iran and malaria cases are reported in this area year-round with peaks after the two annual rainy seasons (April-June and September-December) [15].

\section{Mosquito collection and rearing}

Since An. stephensi is the main malaria vector in the south of Iran, insecticide tests were performed on this species during spring and fall 2014. Anopheline larvae were collected at different times during the mosquito breeding season from December 2013 to August 2014 from different habitats such as river streams, water puddles, and stagnant water areas where the probability to find larvae is high. The larvae samples were transferred to the laboratory and reared to adult stage under standard conditions at $25-29{ }^{\circ} \mathrm{C}, 12: 12$ light: dark photocycle, and $50-70 \%$ relative humidity in the insectary of Bandar-Abbas Health School. Larvae were reared in plastic trays $(35 \times 25 \times 10 \mathrm{~cm})$ containing 2.51 of deionized water at a density of approximately 100 larvae/l and fed with fish food. Pupae were transferred to screened cages and emerged adults were fed with $10 \%$ sugar solution. The F1 progeny when 2-3-day-old sugar-fed females were used for the tests. Mosquitoes were identified morphologically using standard keys used for the identification of anopheles of Iran [16].

\section{Insecticide susceptibility tests}

Insecticide susceptibility tests were carried out using the WHO susceptibility test kits and standard procedures with four replicates of 25 adult female mosquitoes per test tube [17]. Mosquitoes were exposed to papers impregnated with the WHO-recommended discriminating concentrations of six insecticides including DDT (4\%), malathion (5 \%), lambda-cyhalothrin (0.05\%), deltamethrin $(0.05 \%)$ and permethrin $(0.75 \%)$ (supplied by WHO). Mineral oil, olive oil and silicon oil impregnated papers were respectively used for organochlorine, organophosphate and pyrethroid insecticides as controls [17].

The exposure time for each insecticide was $1 \mathrm{~h}$. The mortality rate was calculated after a $24 \mathrm{~h}$ of recovery period. For those insecticides that the observed mortalities in the test were below $90 \%$, mortality rates in various time intervals were also calculated and then regression lines were plotted. $\mathrm{KDT}_{50}$ and $\mathrm{KDT}_{90}$ values were calculated using Probit analysis. Error bars for each mortality rate were calculated based on statistical method at $\alpha=5 \%$.

\section{Statistical analysis}

Mortality was determined by counting the dead and alive mosquitoes at the end of the $24 \mathrm{~h}$ of recovery period. The mortality then was corrected by applying Abbott's formula when control mortality was recorded between 5 and $20 \%$, while tests with $>20 \%$ control mortality were discarded and repeated [18]. Resistance was defined according to WHO guidelines which suggests that 98-100 \% mortality indicates susceptibility, 90-97\% indicates the possibility of resistance that needs to be confirmed, and $<90 \%$ indicates resistance [17].

\section{Results}

A total of 1500 female mosquitoes, reared from larvae collected in different habitats (Fig. 3), were exposed to insecticides belonging to the three WHO approved classes. 


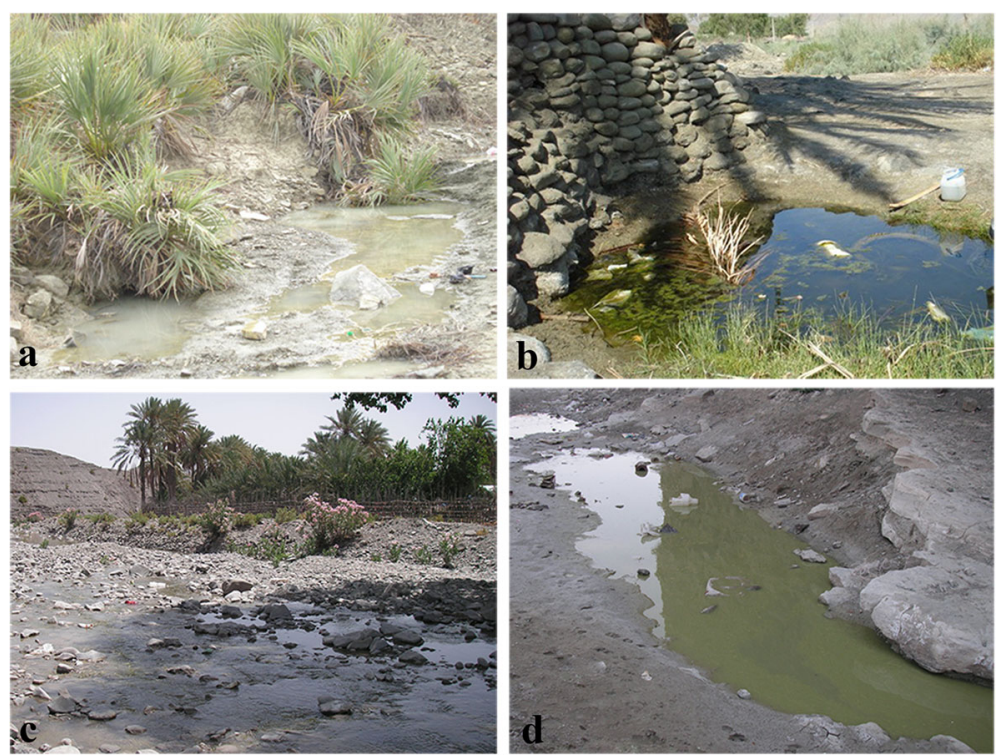

Fig. 3 Typical potential anopheline larval habitats in Jack county, southeastern Iran. a, b Water leakage. c Riverbed. d River edge

The results of susceptibility tests using a threshold of $90 \%$ mortality for resistance confirmation as set by WHO criteria indicated that the natural population of An. stephensi is resistant to DDT. The mortality rate of An. stephensi to DDT was $66 \%$ which indicates a high level of resistance to DDT. The predicted $\mathrm{LT}_{50}$ and $\mathrm{LT}_{90}$ values for this species were 130.25 and $597.35 \mathrm{~min}$, respectively. Mortality rate of An. stephensi mosquitoes that were exposed for $60 \mathrm{~min}$ to $0.05 \%$ lambdacyhalothrin was $86 \%$, indicating the resistance of this species to lambda-cyhalothrin. The predicted $\mathrm{LT}_{50}$ and $\mathrm{LT}_{90}$ values of lambda-cyhalothrin against An. stephensi were 37.71 and $71.12 \mathrm{~min}$, respectively. The results of the study on the efficacy of DDT and lambdacyhalothrin and regression line parameters are presented in Table 1. Regression line showed a linear relationship between mortality rate and exposure time (Fig. 4).

The results also showed that An. stephensi was susceptible to malathion and permethrin, and tolerant to deltamethrin. The results of insecticide susceptibility tests carried out on An. stephensi mosquitoes are shown in Table 2.

\section{Discussion}

The Iran national malaria control programme has implemented indoor residual spraying with lambdacyhalothrin and deltamethrin insecticides, distribution of long-lasting insecticidal nets and application of larvicides as the main malaria vector control strategies $[1,14,19]$. Development of insecticide resistance in malaria vectors is one of the serious limitations of effective vector control strategies that rely on chemical insecticides. It has been reported that rapid emergence and geographical spread of insecticide resistance among malaria vectors has threatened the intervention programmes in many endemic Afro-Asian countries [5, 9, 13]. Therefore, regular monitoring of insecticide susceptibility among endemic malaria vectors is an essential component for the development of an effective vector management plan.

Since An. stephensi is the most prevalent endophilic species and has been confirmed as the main malaria vector in the south of Iran [1], this study conducted to evaluate insecticide susceptibility status of this species against DDT and current insecticides which have been

Table 1 Probit regression line parameters of An. stephensi exposed to DDT (4 \%) and Lambda-cyhalothrin (0.05 \%) in southeastern Iran

\begin{tabular}{|c|c|c|c|c|c|c|}
\hline Insecticides & A & $B \pm S E$ & $\begin{array}{l}\mathrm{LT}_{50} \\
95 \% \text { C.I. } \\
\text { (min) }\end{array}$ & $\begin{array}{l}\mathrm{LT}_{90} \\
95 \% \text { C.I. } \\
\text { (min) }\end{array}$ & $\begin{array}{l}x^{2} \\
(d f)\end{array}$ & $P$-value \\
\hline DDT (4 \%) & -4.097 & $1.94 \pm 0.246$ & 130.25 & 597.35 & $5.23(3)$ & $>0.05$ \\
\hline Lambda-cyhalothrin (0.05 \%) & -7.33 & $4.65 \pm 1.096$ & 37.71 & 71.12 & $16.44(2)$ & $<0.05$ \\
\hline
\end{tabular}

Abbreviations: A, intercept; $\mathrm{B}$, slope; $\mathrm{SE}$, standard error; $\mathrm{LT}_{50}, 95 \% \mathrm{Cl}$, lethal time causing $50 \%$ mortality and its $95 \%$ confidence interval; $\mathrm{LT}_{90}$, $95 \% \mathrm{Cl}$, lethal time causing $90 \%$ mortality and its $95 \%$ confidence interval; $X^{2}$, heterogeneity about the regression line; df, degrees of freedom 


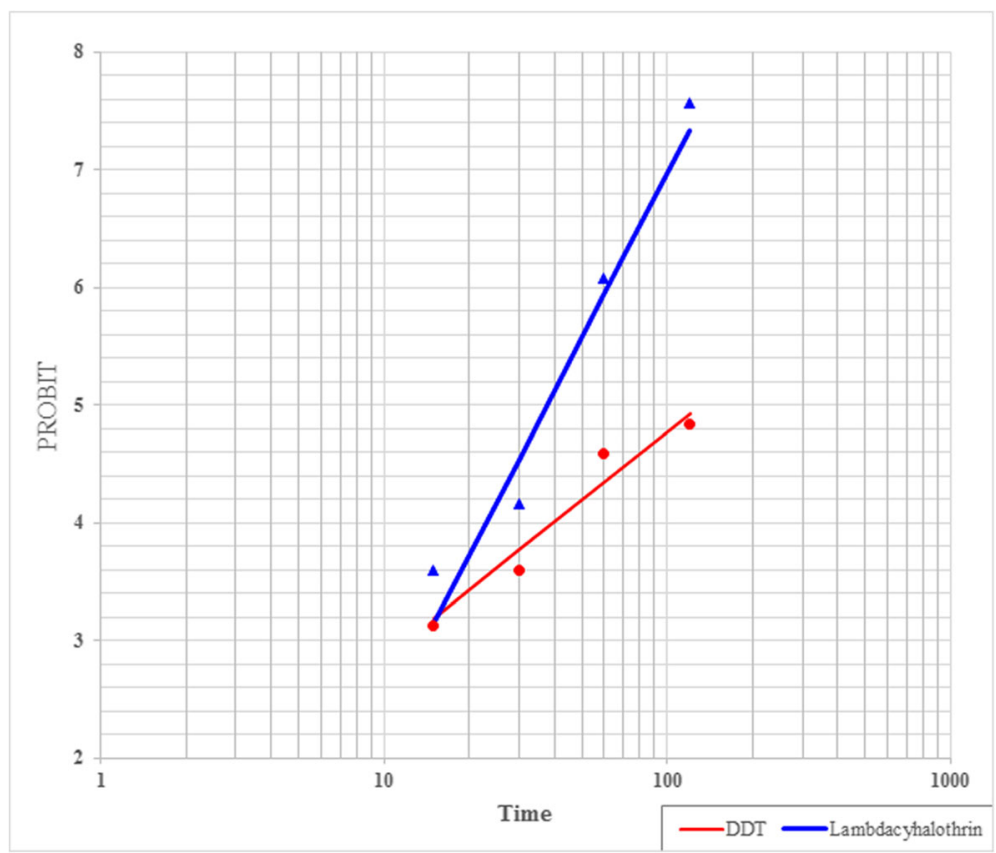

Fig. 4 Regression lines of An. stephensi exposed to DDT (4 \%) and Lambda-cyhalothrin (0.05 \%) in southeastern Iran

used in malaria control programs. In this study, An. stephensi was found resistant to DDT. This finding is in agreement with previous studies conducted in the malarious areas of southern Iran [20]. In Iran, insecticide resistance of this species to DDT was reported for the first time in 1957. Recent studies in Chabahar and Bashagard, the neighbouring counties of the study area, have shown that An. stephensi is resistant to DDT [13, 20]. Moreover, susceptibility tests in neighbouring countries including Afghanistan, Pakistan, Iraq, Oman, United Arab Emirates, and Saudi Arabia have shown resistance of $A n$. stephensi to DDT [21]. Anopheles stephensi is sufficiently endophilic and endophagic to come into contact with insecticide residues in houses and therefore insecticide resistance in this species can be explained by the widespread use of DDT house spraying in different areas of Iran during the malaria eradication campaign in 1950s [13, 20]. Although there is no report of crossresistance between DDT and pyrethroids, it seems widespread use of pesticides in agricultural activities and increased coverage of LLINs as a malaria vector control measure can potentially lead to such cross-resistance.

Table 2 Insecticide susceptibility status of natural population of An. stephensi in southeastern Iran

\begin{tabular}{|c|c|c|c|c|c|c|c|c|}
\hline \multirow[t]{2}{*}{ Insecticide (\%) } & \multirow{2}{*}{$\begin{array}{l}\text { Exposure } \\
\text { time } \\
\text { (min) }\end{array}$} & \multicolumn{3}{|l|}{ Treatment } & \multicolumn{3}{|l|}{ Control } & \multirow{2}{*}{$\begin{array}{l}\text { Resistance } \\
\text { status }\end{array}$} \\
\hline & & $\begin{array}{l}\text { No. exposed } \\
\text { (Replicates) }\end{array}$ & No. dead & Mortality rate (\%) & $\begin{array}{l}\text { No. exposed } \\
\text { (Replicates) }\end{array}$ & No. dead & Mortality rate (\%) & \\
\hline \multirow[t]{4}{*}{$\overline{\text { DDT (4 \%) }}$} & 15 & $100(4)$ & 3 & 3 & $50(2)$ & 0 & 0 & \multirow[t]{4}{*}{$\mathrm{R}$} \\
\hline & 30 & $100(4)$ & 8 & 8 & $50(2)$ & 0 & 0 & \\
\hline & 60 & $100(4)$ & 34 & 34 & $50(2)$ & 0 & 0 & \\
\hline & 120 & $100(4)$ & 52 & 52 & $50(2)$ & 4 & 4 & \\
\hline \multirow[t]{4}{*}{ Lambda-cyhalothrin (0.05 \%) } & 15 & $100(4)$ & 8 & 8 & $50(2)$ & 0 & 0 & \multirow[t]{4}{*}{$\mathrm{R}$} \\
\hline & 30 & $100(4)$ & 20 & 20 & $50(2)$ & 0 & 0 & \\
\hline & 60 & $100(4)$ & 86 & 86 & $50(2)$ & 0 & 0 & \\
\hline & 120 & $100(4)$ & 100 & 100 & $50(2)$ & 3 & 3 & \\
\hline Deltamethrin (0.05 \%) & 60 & $100(4)$ & 95 & 95 & $50(2)$ & 0 & 0 & $\mathrm{~T}$ \\
\hline Permethrin (0.75 \%) & 60 & $100(4)$ & 100 & 100 & $50(2)$ & 5 & 5 & S \\
\hline Malathion (5 \%) & 60 & $100(4)$ & 100 & 100 & $50(2)$ & 2 & 2 & S \\
\hline
\end{tabular}


The results of this study indicated the susceptibility of An. stephensi to malathion. Although resistance of this species to malathion had been previously reported from the south of Iran in 1976, reduction of resistance of $A n$. stephensi to malathion has been well-notified in the recent years by various researchers [20].

The results of this study also revealed the resistance of An. stephensi to lambda-cyhalothrin, tolerance to deltamethrin, and sensitivity to permethrin. Approximately in all previous conducted studies on An. stephensi in Iran, susceptibility to pyrethroids has been reported, but in 2012 the first indication of this species resistance to pyrethroid insecticides was reported from the southeastern parts of the country [13]. Moreover, the results of a recent study in Chabahar county in Sistan va Baluchestan Province showed that this species is resistant to lambdacyhalothrin and tolerant to deltamethrin with mortality rates of 89 and $96 \%$, respectively [22]. Similar findings have been reported from malaria endemic areas in Afghanistan [23]. Synthetic pyrethroids including deltamethrin and lambda-cyhalothrin are being widely used in various public health programmes to control mosquitoes in many countries. However, in the recent years the efficacy of these insecticides against potential malaria vectors has been found to be reduced in endemic areas $[24,25]$. In this regard, resistance of the malaria vectors to pyrethroids have been reported from some Afrotropical regions including Mozambique, Uganda, southern Africa, Benin and Ghana [26].

Resistance of An. stephensi against lambda-cyhalothrin in this study may be explained by massive use of these insecticides in IRS during past years and its tolerance to deltamethrin which was found in this study may be due to large scale distribution of deltamethrin-impregnated LLINs and its use in house spraying applications during recent years. Moreover it seems that repeated use of pyrethroid insecticides as agricultural pesticides has resulted in a selection pressure on mosquito populations in the study area leading to the development of insecticide resistance. Similar trends have been reported from Middle East different regions, Indian subcontinent, and many African malaria endemic countries [23, 24, 27]. The use of pyrethroids as pesticides in agriculture and bed-net treatment has been recognized as factors responsible for the natural selection of resistant mosquitoes in subSaharan Africa [26, 28].

The results of this study showed the resistance of $A n$. stephensi as the main malaria vector to pyrethroid insecticides in the southeast of Iran. The emergence and rapid spread of insecticide resistance in Anopheles population may impair the effectiveness of malaria vector control measures which are based on the use of LLINs and IRS and therefore threaten the sustainability of the current strategies for malaria elimination $[26,29,30]$.
Therefore, to implement a successful malaria control program it is vital to take into account the implications of insecticide resistance to pyrethroids. In this regard, utilization of biochemical and molecular assays are recommended to understand the mechanisms of pyrethroid resistance in An. stephensi to implement targeted vector control interventions and predict the origin and likely impact of the resistance.

\section{Conclusion}

This study confirms the resistance of the major malaria vector, An. stephensi, to DDT and lambda-cyhalothrin and reduced susceptibility to deltamethrin which could gradually increase and spread into other malaria endemic areas. Since the resistance level of An. stephensi against insecticides may decrease the efficacy of LLINs and IRS, there is a need for regular monitoring of current insecticides resistance in order to select suitable insecticides for vector control interventions towards malaria elimination. In this regard, resistance management strategies including rotations of insecticides, use of interventions in combination, mosaic spraying, and use of mixtures should be considered to control insecticide resistance in the Anopheles population in malaria endemic areas to improve malaria elimination programs.

\section{Abbreviations}

IRS: Indoor residual spraying; LLINs: Long-lasting insecticidal nets

\section{Acknowledgements \\ The authors would like to appreciate the collaboration received from personnel of the Jask Health Center for their cooperation in the field. We especially thank Mr. AbdulRasool Mojahedi, and Mr. Hassan Javdan for their assistance in larval rearing and laboratory works.}

\section{Funding}

This research has been funded by Research Deputy of Hormozgan University of Medical Sciences (Project No. 4679).

\section{Availability of data and material}

The dataset supporting the conclusions of this article is included within the article.

Authors' contributions

MZ, MSA, ASD and SHD conceived and designed the study. MZ, MSA, and SHD drafted the manuscript. MSA and ASD analyzed the data. MSA coordinated in field activity, collected data and trained field researcher. All authors read and approved the final manuscript.

\section{Competing interests}

The authors declare that they have no competing interests.

Consent for publication

Not applicable.

Ethics approval and consent to participate Not applicable.

\section{Author details}

'Department of Occupational Health Engineering, Faculty of Health, Hormozgan University of Medical Sciences, Bandar Abbas, Iran. ${ }^{2}$ Social Determinants in Health Promotion Research Center, Hormozgan University of Medical Sciences, Bandar Abbas, Iran. ${ }^{3}$ Department of Medical Entomology 
and Vector Control, Faculty of Health, Hormozgan University of Medical Sciences, P.O. Box: 79145-3838, Bandar Abbas, Iran. ${ }^{4}$ Department of Nutrition Research, National Nutrition and Food Technology Research Institute, Faculty of Nutrition Sciences and Food Technology, Shahid Beheshti University of Medical Sciences, Tehran, Iran

Received: 13 July 2016 Accepted: 18 October 2016

Published online: 04 November 2016

\section{References}

1. Soleimani-Ahmadi M, Vatandoost $H$, Zare M, Turki $H$, Alizadeh A. Topographical distribution of anopheline mosquitoes in an area under elimination programme in the south of Iran. Malar J. 2015;14:262.

2. Soleimani-Ahmadi M, Vatandoost $H$, Zare M. Characterization of larval habitats for anopheline mosquitoes in a malarious area under elimination program in the southeast of Iran. Asian Pac J Trop Biomed. 2014;4 Suppl 1:73-80.

3. Soleimani-Ahmadi M, Vatandoost H, Hanafi-Bojd AA, Zare M, Safari R, Mojahedi A, et al. Environmental characteristics of anopheline mosquito larval habitats in a malaria endemic area in Iran. Asian Pac J Trop Med. 2013;6(7):510-5

4. Djadid ND, Forouzesh F, Karimi M, Raeisi A, Hassan-Zehi A, Zakeri S. Monitoring pyrethroid insecticide resistance in major malaria vector Anopheles culicifacies: comparison of molecular tools and conventional susceptibility test. Iran Biomed J. 2007;11(3):169-76.

5. WHO. World Malaria Report 2015. Geneva: World Health Organization; http://www.who.int/malaria/publications/world-malaria-report-2015/report/ en/. Accessed 23 May 2016.

6. Soleimani-Ahmadi M, Vatandoost H, Zare M, Alizadeh A, Salehi M. Community knowledge and practices regarding malaria and long-lasting insecticidal nets during malaria elimination programme in an endemic area in Iran. Malar J. 2014:13:511.

7. Kabula B, Tungu P, Matowo J, Kitau J, Mweya C, Emidi B, et al. Susceptibility status of malaria vectors to insecticides commonly used for malaria control in Tanzania. Trop Med Int Health. 2012;17(6):742-50.

8. White MT, Conteh L, Cibulskis R, Ghani AC. Costs and cost-effectiveness of malaria control interventions: a systematic review. Malar J. 2011;10:337.

9. Raghavendra K, Barik TK, Reddy BP, Sharma P, Dash AP. Malaria vector control: from past to future. Parasitol Res. 2011;108(4):757-79.

10. Zaim M, Aitio A, Nakashima N. Safety of pyrethroid-treated mosquito nets. Med Vet Entomol. 2000;14(1):1-5.

11. Santolamazza F, Calzetta M, Etang J, Barrese E, Dia I, Caccone A, et al. Distribution of knock-down resistance mutations in Anopheles gambiae molecular forms in west and west-central Africa. Malar J. 2008;7:74.

12. WHO. Global plan for insecticide resistance management in malaria vectors (GPIRM). Geneva: World Health Organization; 2012. http://apps.who.int/iris/ bitstream/10665/44846/1/9789241564472 eng.pdf. Accessed 21 June 2016.

13. Vatandoost $H$, Hanafi-Bojd AA. Indication of pyrethroid resistance in the main malaria vector, Anopheles stephensi from Iran. Asian Pac J Trop Med. 2012;5(9):722-6

14. Soleimani-Ahmadi M, Vatandoost $H$, Shaeghi M, Raeisi A, Abedi $F$, Eshraghian MR, et al. Field evaluation of permethrin long-lasting insecticide treated nets $\left(\right.$ Olyset $\left.^{\oplus}\right)$ for malaria control in an endemic area, southeast of Iran. Acta Trop. 2012;123(3):146-53.

15. Yeryan M, Basseri HR, Hanafi-Bojd AA, Raeisi A, Edalat H, Safari R. Bio-ecology of malaria vectors in an endemic area, Southeast of Iran. Asian Pac J Trop Med. 2016;9(1):32-8

16. Azari-Hamidian S, Harbach RE. Keys to the adult females and fourthinstar larvae of the mosquitoes of Iran (Diptera: Culicidae). Zootaxa. 2009:2078:1-33.

17. WHO. Malaria Entomology and Vector Control. Participant's Guide, Test procedures for insecticide resistance monitoring in malaria vector mosquitoes. Geneva: World Health Organization; 2013. http://apps.who.int/ iris/bitstream/10665/80139/1/9789241505154_eng.pdf. Accessed 29 June 2016.

18. Abbott WS. A method of computing the effectiveness of an insecticide. J Econ Entomol. 1925;18:265-7.

19. Salim Abadi Y, Vatandoost H, Rassi Y, Abai MR, Sanei-Dehkordi AR, Paksa A. Evaluation of biological control agents for mosquitoes control in artificial breeding places. Asian Pac J Trop Med. 2010;3(4):276-7.

20. Soleimani-Ahmadi M, Vatandoost H, Shaeghi M, Raeisi A, Abedi F, Eshraghian MR, et al. Vector ecology and susceptibility in a malaria-endemic focus in southern Islamic Republic of Iran. East Mediterr Health J. 2012;18(10):1034-41.

21. WHO. Vector resistance to pesticides: fifteenth report of the WHO Expert Committee on Vector Biology and Control, meeting held in Geneva from 5 to 12 March 1991. Geneva: World Health Organization; 1992. WHO Technica Report Series, No. 818.

22. Gorouhi MA, Vatandoost $H$, Oshaghi MA, Raeisi A, Enayati AA, Mirhendi $H$, et al. Current susceptibility status of Anopheles stephensi (Diptera: Culicidae) to different imagicides in a malarious area, southeastern Iran. J Arthropod Borne Dis. 2016 (In Press).

23. Ahmad M, Buhler C, Pignatelli P, Ranson H, Nahzat SM, Naseem M, et al. Status of insecticide resistance in high-risk malaria provinces in Afghanistan. Malar J. 2016;15:98.

24. Dhiman S, Yadav K, Rabha B, Goswami D, Hazarika S, Tyagi V. Evaluation of insecticides susceptibility and malaria vector potential of Anopheles annularis s.l. and Anopheles vagus in Assam, India. PLoS One. 2016;11(3):e0151786.

25. Verhaeghen K, Van Bortel W, Trung H, Sochantha T, Keokenchanh K, Coosemans M. Knockdown resistance in Anopheles vagus, An. sinensis, An. paraliae and An. peditaeniatus populations of the Mekong region. Parasit Vectors. 2010;3(1):59.

26. Ole Sangba ML, Deketramete T, Wango SP, Kazanji M, Akogbeto M Ndiath MO. Insecticide resistance status of the Anopheles funestus population in Central African Republic: a challenge in the war. Parasit Vectors. 2016;9(1):230

27. Knox TB, Juma EO, Ochomo EO, Pates Jamet $H$, Ndungo $L$, Chege $P$, et al. An online tool for mapping insecticide resistance in major Anopheles vectors of human malaria parasites and review of resistance status for the Afrotropical region. Parasit Vectors. 2014;7:76.

28 Czeher C, Labbo R, Arzika I, Duchemin JB. Evidence of increasing Leu-Phe knockdown resistance mutation in Anopheles gambiae from Niger following a nationwide long-lasting insecticide-treated nets implementation. Malar J. 2008;7:189.

29 Trape JF, Tall A, Diagne N, Ndiath O, Ly AB, Faye J, et al. Malaria morbidity and pyrethroid resistance after the introduction of insecticide-treated bednets and artemisinin-based combination therapies: a longitudinal study. Lancet Infect Dis. 2011:11(12):925-32.

30 Sokhna C, Ndiath $\mathrm{MO}$, Rogier $\mathrm{C}$. The changes in mosquito vector behaviour and the emerging resistance to insecticides will challenge the decline of malaria. Clin Microbiol Infect. 2013;19(10):902-7.

\section{Submit your next manuscript to BioMed Central and we will help you at every step:}

- We accept pre-submission inquiries

- Our selector tool helps you to find the most relevant journal

- We provide round the clock customer support

- Convenient online submission

- Thorough peer review

- Inclusion in PubMed and all major indexing services

- Maximum visibility for your research

Submit your manuscript at www.biomedcentral.com/submit 